DELGADO, Joedson de Souza. A governança da justiça e da segurança na sociedade de risco contemporânea. Revista Eletrônica Direito e Política, Programa de Pós-Graduação Stricto Sensu em Ciência Jurídica da UNIVALI, Itajaí, v.11, n.1, $1^{0}$ quadrimestre de 2016. Disponível em: www.univali.br/direitoepolitica - ISSN 1980-7791.

\title{
A GOVERNANÇA DA JUSTIÇA E DA SEGURANÇA NA SOCIEDADE DE RISCO CONTEMPORÂNEA
}

THE GOVERNANCE OF JUSTICE AND SECURITY IN TODAY'S RISK SOCIETY

Joedson de Souza Delgado ${ }^{1}$

\begin{abstract}
RESUMO
A promoção da segurança há muito tempo deixou de ser um monopólio estatal. Encontram-se dispersos e realizam-se através de diversos atores sociais lado a lado 'com o governo'. Mas o que sabemos sobre as maneiras em que a segurança é pensada e promovida neste campo pluralizado? O texto possui como tema a compreensão das regras de governança da justiça criminal e da segurança pública contemporânea. A partir da análise do discurso de Johnston e Shearing, inclusive que esses autores fazem de Beccaria, oferecem uma interlocução entre aqueles que argumentam que a transformação democrática assenta no desenvolvimento de instituições estatais fortes e os que propõem o renascimento da indústria de segurança privada, para tanto, situam-se as análises teóricas para suportar em exemplos empíricos.
\end{abstract}

PALAVRAS-CHAVES: Promoção da segurança. Monopólio estatal. Regras de governança. Segurança privada.

\section{ABSTRACT}

Promoting safety long ago ceased to be a state monopoly. They are dispersed and are held through various social actors side by side 'with the government. " But what we know about the ways in which security is conceived and promoted pluralized in this field? The text has as its theme the understanding of the governance rules of criminal justice and contemporary public safety. From the Johnston discourse analysis and Shearing, including those authors of Beccaria, they offer a dialogue between those who argue that the democratic transformation based on the development of strong state institutions and those who propose the revival of the private security industry, Therefore, we find the theoretical analysis to bear on empirical examples.

\footnotetext{
1 Mestrando em Direito pelo Centro Universitário de Brasília - UniCEUB. Especialista em Direito Sanitário pela Fundação Oswaldo Cruz - Fiocruz e em Direito Administrativo pelo Instituto Brasiliense de Direito Público - IDP. Administrador graduado pela Universidade de Brasília - UnB e advogado pelo Centro Universitário do Distrito Federal - UDF. Analista Administrativo na Agência Nacional de Vigilância Sanitária - Anvisa. E-mail: joedson.delgado@hotmail.com
} 
DELGADO, Joedson de Souza. A governança da justiça e da segurança na sociedade de risco contemporânea. Revista Eletrônica Direito e Política, Programa de Pós-Graduação Stricto Sensu em Ciência Jurídica da UNIVALI, Itajaí, v.11, n.1, $1^{0}$ quadrimestre de 2016. Disponível em: www.univali.br/direitoepolitica - ISSN 1980-7791.

KEYWORDS: Safety Promotion. State monopoly. Governance rules. Private security.

\section{INTRODUÇÃO}

A política criminal sistematizada por Cesare Beccaria visava garantir que os cidadãos se abstivessem de comportamentos antissociais e que o Estado produzisse felicidade para o maior número possível de pessoas através de ordenamentos claros/coerentes com sanções proporcionais e que os estatutos desconhecidos, julgamentos injustos e as punições cruéis pertencessem ao passado. Beccaria repensou a sistemática penal no século XVIII influenciado pelo movimento filosófico conhecido como Iluminismo cuja vontade racional aparentemente foi amplamente alcançada em várias sociedades contemporâneas por intermédio das leis penais codificadas, de uma justiça criminal imparcial e independente e da condenação, com base em princípios desenvolvidos ao longo dos últimos três séculos².

No contexto político atual completamente diverso de Beccaria, isto é, da passagem de uma monarquia corporativa para uma monarquia absolutista, cujos objetivos e desafios são completamente diferentes dos quais a sociedade contemporânea enfrenta argumenta-se que o monopólio estatal da violência pela governança da justiça criminal e da segurança pública foi perdido. A principal razão é o desenvolvimento global da sociedade e que uma série de atores (primeiro, segundo e terceiro setores), incluindo o próprio cidadão, buscam se proteger em forma de rede de segurança particular - por cooperação.

Dupont define rede de segurança como

conjunto de atores institucionais, organizacionais, comunitários ou individuais conectados direta ou indiretamente a fim de autorizar e/ou de produzir a

\footnotetext{
${ }^{2}$ RI JÚNIOR, Arno Dal; CASTRO, Alexander de. Iluminismo e absolutismo no modelo jurídico-penal de Cesare Beccaria. In: Revista Seqüência, n. 57, p. 262-264, dez. 2008. Disponível em: <http://dx.doi.org/10.5007/2177-7055.2008v29n57p261>. Acesso em: 13 nov. 2015.
} 
DELGADO, Joedson de Souza. A governança da justiça e da segurança na sociedade de risco contemporânea. Revista Eletrônica Direito e Política, Programa de Pós-Graduação Stricto Sensu em Ciência Jurídica da UNIVALI, Itajaí, v.11, n.1, $1^{0}$ quadrimestre de 2016. Disponível em: www.univali.br/direitoepolitica - ISSN 1980-7791.

segurança por conta dos interesses coletivos (a população) ou particulares (um cliente) ${ }^{3}$.

A independência do indivíduo e sua maior conscientização de que o governo não é o único ator decisivo das questões sociais - a exemplo da infiltração das drogas ilícitas em todas as camadas da sociedade - torna o direito penal apenas uma das muitas ferramentas de proteção. A condução política da segurança está menos preocupada com as respostas da justiça criminal ao comportamento antecedente e se concentra na redução de danos no futuro, isto é, punir comportamentos prejudiciais à sociedade é considerado de interesse apenas se conduzir a redução do risco.

A principal razão que o modelo teórico de Beccaria não se encontra inteiramente implantado poderia ser buscada na inadequação da lei penal, uma vez que está equipada com os seus princípios racionais. Proclamar leis cognoscíveis e fazer cumprir essas leis por meio de punição proporcional não está suficientemente comprovado que protege eficazmente os cidadãos. O Estado não é capaz de responder adequadamente através do direito penal em todos os comportamentos antissociais, no entanto, a sociedade de risco ${ }^{4}$ exige cidadãos e empresas com maiores proteções estatais do que o direito penal pode oferecer. É por tal razão que o cidadão e as empresas procuram alternativas para a ação inadequada do governo.

Marins denomina tal fenômeno como a privatização da autoridade, delegação de hard core functions, "atomização" da esfera pública e contratualização do poder administrativo $^{5}$. Nesta mesma esteira, Garland assevera que a responsabilização dos indivíduos em matéria de repreensão criminal repercute em

3 DUPONT, Benoît. As redes de segurança. In: SLAKMON, Catherine; MACHADO, Maíra Rocha; BOTTINI, Pierpaolo Cruz (Org.). Novas direções na governança da justiça e da segurança. Brasília-DF: Ministério da Justiça, 2006, p. 709. Disponível em: <http://www.esteio.rs.gov.br/documents/SMSMU/governanca\%20na\%20seguranca\%20\%20material\%20do\%20MJ.pdf >. Acesso em: 8 set. 2015.

${ }^{4}$ Sociedade de risco é uma expressão cunhada por Beck ligada a uma nova ordem global cujos problemas são igualitários e perpassam Estados e classes sociais delimitados por fanatismo religioso, crises econômicas, alto desemprego, concentração de riqueza e pobreza em massa. (BECK, Ulrich. World risk society. Cambridge: Polity Press, 1999, p. 2-7.).

${ }^{5}$ MARINS, Vinicius. Contratação de serviços de segurança privada pela administração pública: uma análise à luz da moderna privatização de poderes administrativos. In: Revista do Tribunal de 
DELGADO, Joedson de Souza. A governança da justiça e da segurança na sociedade de risco contemporânea. Revista Eletrônica Direito e Política, Programa de Pós-Graduação Stricto Sensu em Ciência Jurídica da UNIVALI, Itajaí, v.11, n.1, $1^{0}$ quadrimestre de 2016. Disponível em: www.univali.br/direitoepolitica - ISSN 1980-7791.

reduzir a dependência do Estado, mas aumenta simultaneamente a dependência em relação ao mercado e ao capital privado. O investimento na criminalidade e os dispositivos de segurança são, portanto, impostos cada vez mais por forças econômicas do que pela politica pública ${ }^{6}$.

Esse fato é comum às firmas que, para se proteger, contratam serviços especializados, a fim de manter a segurança nas chamadas propriedades privadas coletivas (estádios esportivos, parques de diversões, centros comerciais, escritórios, etc.) com vistas a reduzir comportamentos nocivos (como roubo e furtos de funcionários e clientes). Os cidadãos que podem pagar se reclusam em condomínios fechados, com a contratação de segurança privada ou desenvolvem outras medidas estratégicas de segurança extragoverno para garantir seu patrimônio, incluindo a instalação de câmeras de segurança em áreas comuns e a criação de espaço para entrega de objetos à portaria sem abertura do portão.

Diante destes aprimoramentos que visa à segurança dos cidadãos, a descentralização desta atividade tipicamente estatal levanta o questionamento das medidas alternativas de governança pública capazes de fornecer segurança equânime aos cidadãos e em que medida a segurança alternativa é eficaz.

O objetivo deste ensaio é examinar a manutenção da governança da justiça e da segurança pública na atual sociedade de risco relativo à eficácia e a normatividade da potestade administrativa através da codificação penal. Necessário, então, fazer uma reconstrução histórica do significado paradigmático de Beccaria em seu tempo para, em seguida, tecer uma reconstrução racional dos pressupostos que fundamentam sua opinião, bem como a conexão com concepções modernas de racionalidade e justiça.

Antes de discutir o pensamento de Beccaria devem-se refletir os pontos de vista de Johnston e Shearing sobre a erosão da soberania estatal e o surgimento da

Contas do Estado de Minas Gerais. v. 74, n. 1, p. 79 a 102, ano XXVIII, 2010. Disponível em: <http://revista.tce.mg.gov.br/Content/Upload/Materia/854.pdf>. Acesso em: 8 set. 2015.

6 GARLAND, David. Ad contradições da "sociedade punitiva": o caso britânico. Discursos sediciosos: crime, direito e sociedade. a. 7, n. 11. Rio de Janeiro: Editora Revan, 2002, p. 81. 
DELGADO, Joedson de Souza. A governança da justiça e da segurança na sociedade de risco contemporânea. Revista Eletrônica Direito e Política, Programa de Pós-Graduação Stricto Sensu em Ciência Jurídica da UNIVALI, Itajaí, v.11, n.1, 10 quadrimestre de 2016. Disponível em: www.univali.br/direitoepolitica - ISSN 1980-7791.

governança de justiça e de segurança ${ }^{7}$. Johnston e Shearing consideram Beccaria como o principal representante do direito penal clássico que perdeu importância na atual sociedade em rede $^{8}$ que se baseia em uma mentalidade de risco ao trazer sensação de justiça por técnicas alternativas de não punição ${ }^{9}$. Consideram punir o crime anteriormente praticado apenas como uma ferramenta para reduzir o risco de danos. A lei penal deve, assim, competir com muitos outros instrumentos da governança de justiça e de segurança.

\section{GOVERNANÇA DA JUSTIÇA CRIMINAL E DA SEGURANÇA PÚBLICA}

No manuscrito As redes de segurança, Dupont argumenta metaforicamente que o monopólio estatal da segurança deu lugar a estruturas em que os governos, as empresas e os cidadãos trabalham juntos para se protegerem como uma teia ${ }^{10}$. Dessa forma, as distinções entre as tarefas de segurança pública prestada pelas autoridades públicas e o mercado privado se encurtaram e, em algumas situações, desapareceram. O governo tem utilizado cada vez mais as empresas, por meio da contratação de serviços de proteção nominada de segurança orgânica, segundo uma análise tradicional, reputada como exclusivas do Estado.

Zanetic relata que os serviços de segurança privada são circunscritos na sua atuação quanto à vedação de policiar ostensivamente em áreas públicas, atividade esta, no Brasil, restrita as polícias militares, conforme art. $144, \S 50$ da

\footnotetext{
7 JOHNSTON, Les; SHEARING, Clifford. A justiça em sociedades de risco. In: SLAKMON, Catherine; MACHADO, Maíra Rocha; BOTTINI, Pierpaolo Cruz (Org.). Novas direções na governança da justiça e da segurança. Brasília-DF: Ministério da Justiça, 2006, p. 135. Disponível em: <http://www.esteio.rs.gov.br/documents/SMSMU/governanca\%20na\%20seguranca\%20\%20material\%20do\%20MJ.pdf >. Acesso em: 8 set. 2015.

8 JOHNSTON, Les; SHEARING, Clifford. A justiça em sociedades de risco. In: SLAKMON, Catherine; MACHADO, Maíra Rocha; BOTTINI, Pierpaolo Cruz (Org.). Novas direções na governança da justiça e da segurança.

9 JOHNSTON, Les; SHEARING, Clifford. A justiça em sociedades de risco. In: SLAKMON, Catherine; MACHADO, Maíra Rocha; BOTTINI, Pierpaolo Cruz (Org.). Novas direções na governança da justiça e da segurança.

10 JOHNSTON, Les; SHEARING, Clifford. A justiça em sociedades de risco. In: SLAKMON, Catherine; MACHADO, Maíra Rocha; BOTTINI, Pierpaolo Cruz (Org.). Novas direções na governança da justiça e da segurança.
} 
DELGADO, Joedson de Souza. A governança da justiça e da segurança na sociedade de risco contemporânea. Revista Eletrônica Direito e Política, Programa de Pós-Graduação Stricto Sensu em Ciência Jurídica da UNIVALI, Itajaí, v.11, n.1, 10 quadrimestre de 2016. Disponível em: www.univali.br/direitoepolitica - ISSN 1980-7791.

Constituição Federal ${ }^{11}{ }^{12}$. Portanto, as funções de policiamento privado devem ter o consentimento do proprietário firmado em contrato entre as partes.

O Poder Público perdeu seu status exclusivo de proteção no sentido de que, por exemplo, o policiamento é apenas um instrumento de segurança entre muitas utilizadas por empresas e indivíduos. Na gestão de conflitos, os cidadãos e organizações não querem depender da estrutura de repressão criminal do governo, mas espontaneamente organizar a sua segurança. Neste sentido, Johnston e Shearing entendem que o governo deve cada vez mais desenvolver ferramentas e estratégias que visam principalmente à redução de riscos de segurança e não somente punir os transgressores de crimes anteriores ${ }^{13}$.

Johnston e Shearing descrevem estes desenvolvimentos em termos de programas de segurança, onde se diferenciam entre o programa punitivo clássico em que o direito penal tem uma função central e do programa de risco de segurança em que o governo perdeu o monopólio da segurança ${ }^{14}$. O principal instrumento dessas instituições (polícia, Ministério Público, tribunais, órgão executivo) é a punição (prisão/multa) utilizada em caso de violação da lei, sendo que o direito penal corrente exprime uma mentalidade punitiva que se deriva da ordem pública e da incolumidade das pessoas e patrimônio delimitados pelo Texto Constitucional. A mentalidade punitiva, de acordo com Johnston e Shearing, foca-se no passado: mantendo instituições penais principalmente preocupados com a apuração, acusação, julgamento e punição dos fatos que já ocorreram e a pena é, em grande parte, determinada pela natureza da infração e da personalidade do agressor ${ }^{15}$.

\footnotetext{
${ }^{11}$ ZANETIC, André. Segurança privada: características do setor e impacto sobre o policiamento. In: Revista Brasileira de Segurança Pública. Ano 3, ed. 4, mar/abr 2009, p. 140. Disponível em: <http://revista.forumseguranca.org.br/index.php/rbsp/article/view/44/42>. Acesso em: 8 set. 2015.

12 BRASIL. Constituição da República Federativa do Brasil (1988). Diário Oficial [da] República Federativa do Brasil, Brasília, DF, 5 out. 1988. Disponível em: <http://www.planalto.gov.br> Acesso em: 10 set. 2015.

${ }^{13}$ BRASIL. Constituição da República Federativa do Brasil (1988). p. 140-141.

${ }^{14}$ BRASIL. Constituição da República Federativa do Brasil (1988). p. 141-144.

${ }^{15}$ BRASIL. Constituição da República Federativa do Brasil (1988). p. 141-144.
} 
DELGADO, Joedson de Souza. A governança da justiça e da segurança na sociedade de risco contemporânea. Revista Eletrônica Direito e Política, Programa de Pós-Graduação Stricto Sensu em Ciência Jurídica da UNIVALI, Itajaí, v.11, n.1, $1^{0}$ quadrimestre de 2016. Disponível em: www.univali.br/direitoepolitica - ISSN 1980-7791.

Medidas preventivas conduzem a uma maneira de pensar o crime - agora percebido como "um acontecimento corriqueiro" que não requer nenhuma justificativa nem ânimo especial, contrariando os discursos criminais anteriores que viam como um desvio comportamental, uma patologia individual ${ }^{16}$-, no entanto, a principal característica do direito penal é o fato de que as instituições lidam com fatos relevantes que já foram cometidos e que, portanto, devem conter uma resposta peculiar à repressão criminal.

Por outro lado, o programa punitivo do direito penal clássico é focado no futuro pela redução do risco de dano a sociedade. Além disso, a justiça criminal, através da ameaça de punição e condenação, desempenha um papel preventivo, entretanto, a punição é sempre muito tardia, porque o dano à coletividade já ocorreu.

As técnicas focadas em riscos são mais focadas em prevenção de danos através de uma variedade de tecnologias de segurança implantadas por empresas, organizações e cidadãos, e também pelos governos, denominadas de "avaliação de risco" e "gestão de risco" que foram desenvolvidas pelas empresas de segurança que cresceram e profissionalizaram seus negócios, tornando-se, por conseguinte, os principais concorrentes do governo em segurança ${ }^{17}$.

Importa consignar que as empresas especializadas também estão adotando Técnicas de Risco sob a forma de técnicas de vigilância utilizadas pelo governo ao usar ferramentas, tais como, a identificação de pessoas por câmeras e da análise de dados de indivíduos e empresas como forma de isolar ou de reduzir riscos.

Certas estratégias são apresentadas pelo governo como formas clássicas de ação governamental, tais como, o Policiamento Comunitário e Tolerância Zero para uma utilização mais segura da polícia em determinadas áreas em que o governo

16 GARLAND, David. Ad contradições da "sociedade punitiva": o caso britânico. Discursos sediciosos: crime, direito e sociedade. a. 7, n. 11. Rio de Janeiro: Editora Revan, 2002, p. 74.

17 GARLAND, David. Ad contradições da "sociedade punitiva": o caso britânico. Discursos sediciosos: crime, direito e sociedade. p. 75-81. 
DELGADO, Joedson de Souza. A governança da justiça e da segurança na sociedade de risco contemporânea. Revista Eletrônica Direito e Política, Programa de Pós-Graduação Stricto Sensu em Ciência Jurídica da UNIVALI, Itajaí, v.11, n.1, $1^{0}$ quadrimestre de 2016. Disponível em: www.univali.br/direitoepolitica - ISSN 1980-7791.

afirma que tem obtido sucesso nessas áreas com as operações policiais intensivas.

$\mathrm{Na}$ análise de Dupont, as parcerias entre governo, cidadãos e empresas são estratégias de risco que não são focadas na execução penal das normas jurídicas, mas para aumentar a segurança em certas áreas utilizam técnicas de vigilância que são adaptadas às necessidades de segurança dos cidadãos e das empresas $^{18}$.

Uma possível objeção da governança da justiça e da segurança é que as tecnologias de segurança têm implantação mais ampla do que a justiça penal tradicional, com seus comportamentos legalmente definidos, responsabilidades e sanção. Destarte, certas técnicas de vigilância não são apenas focadas em pessoas suspeitas de infrações penais, mas em uma categoria maior de pessoas consideradas como grupos de "comportamento antissocial". Por exemplo, na região de Assis, interior de São Paulo, sob o mote da Indiferença Zero, os gestores da Polícia Militar local desenvolveram novas estratégias de policiamento referente à atividade preventiva, particularmente, a qualquer um que esteja em certas áreas "de alto risco" podem estar sujeitas a revistas corporais ${ }^{19}$.

É ponto pacífico a capacidade limitada do Estado na repressão criminal. Garland, então, ilustra que o cidadão promoveu um novo plano situacional em que

se põe a substituir o dinheiro vivo por cartões de crédito, a usar trancas na barra de direção dos carros, a empregar vigias ("guardadores de carro") nos estacionamentos e câmeras de televisão em circuito fechado nos centros comerciais, a coordenar os horários de fechamento das discotecas rivais, a estender o serviço de ônibus noite adentro, a encorajar as autoridades locais a coordenar os diversos organismos que têm a ver com a criminalidade e,

18 GARLAND, David. Ad contradições da "sociedade punitiva": o caso britânico. Discursos sediciosos: crime, direito e sociedade. p. 709-712.

19 LIMA, Lincoln de Oliveira. Estratégias de policiamento preventivo: "indiferença zero", uma boa experiência de polícia. Assis: Triunfal Gráfica e Editora, 2011. 
DELGADO, Joedson de Souza. A governança da justiça e da segurança na sociedade de risco contemporânea. Revista Eletrônica Direito e Política, Programa de Pós-Graduação Stricto Sensu em Ciência Jurídica da UNIVALI, Itajaí, v.11, n.1, $1^{0}$ quadrimestre de 2016. Disponível em: www.univali.br/direitoepolitica - ISSN 1980-7791.

naturalmente, encorajar os cidadãos a ciarem rondas de bairro e outros grupos de auto-defesa ${ }^{20}$.

Em linhas gerais, a tecnologia de segurança da loja tem uma gama maior de utilidade do que o direito penal clássico e, neste caso, o efeito esperado é o controle social pelo constrangimento. A sanção penal é exclusividade de algumas autoridades, por exemplo, polícia, juiz e Ministério Público. Ao fazer isso, Woods e Marks referem-se ao fato de que, embora o policiamento ostensivo como estratégia preventiva do crime foi desenvolvido no passado vem constantemente sofrendo alterações no seu modelo ${ }^{21}$, a exemplo, do mobiliário urbano de policiamento no Distrito Federal denominado de Postos Comunitários de Segurança que foi originariamente desenhando para ser um ponto de referência para a comunidade interagir com o policial, mas que vem sofrendo mudanças da metodologia de trabalho ${ }^{22}$.

Johnston e Shearing identificaram essas objeções da governança da justiça e da segurança, mas a preocupação reside na mitigação do monopólio estatal ${ }^{23}$. No entanto, esta perda traz oportunidades para as pessoas se tornarem menos dependentes do governo e que possam decidir como resolver conflitos dentro de uma comunidade.

Garland menciona um exemplo de um desenvolvimento positivo na Escócia denominado de "desvio na baixa" tido como uma advertência policial como

20 GARLAND, David. Ad contradições da "sociedade punitiva": o caso britânico. Discursos sediciosos: crime, direito e sociedade. a. 7, n. 11. Rio de Janeiro: Editora Revan, 2002, p. 78.

21 WOOD, Jennifer; MARKS, Monique. Governança conexa: desenvolvendo novas ideias para a segurança e a justiça. In: SLAKMON, Catherine; MACHADO, Maíra Rocha; BOTTINI, Pierpaolo Cruz (Org.). Novas direções na governança da justiça e da segurança. Brasília-DF: Ministério da Justiça, 2006, p. 719-737. Disponível em: <http://www.esteio.rs.gov.br/documents/SMSMU/governanca\%20na\%20seguranca\%20$\% 20$ material\%20do\%20MJ.pdf >. Acesso em: 8 set. 2015.

22 ALVES, Luís Cláudio. Audiência discute destinação de postos comunitários de segurança. Disponível em: <http://www.cl.df.gov.br/ultimas-noticias//asset_publisher/ITOh/content/audiencia-discute-destinacao-de-postos-comunitarios-deseguranca; jsessionid=2B76A1A65DF2D8CCDF093DC36C9382DE. liferay2 redirect $=$ http $\% 3 A \% 2 F$ \%2Fwww.cl.df.gov.br\%2Fnoticias>. Acesso em: 11set. 2015.

23 GARLAND, David. Ad contradições da "sociedade punitiva": o caso britânico. Discursos sediciosos: crime, direito e sociedade. p. 132-135. 
DELGADO, Joedson de Souza. A governança da justiça e da segurança na sociedade de risco contemporânea. Revista Eletrônica Direito e Política, Programa de Pós-Graduação Stricto Sensu em Ciência Jurídica da UNIVALI, Itajaí, v.11, n.1, 10 quadrimestre de 2016. Disponível em: www.univali.br/direitoepolitica - ISSN 1980-7791.

resposta à delinquência juvenil em que o promotor apenas instaura processos na metade dos casos relatados a polícia ${ }^{24}$.

Depreende-se, então, que as comunidades locais devem resolver seus conflitos através da justiça restaurativa que não utilizam a coerção do direito penal, mas utiliza de formas alternativas de resolução de litígios. Portanto, é legítimo desenvolver a capacidade local de resolver os conflitos usando os recursos que existem na comunidade, ou seja, sem a participação impositiva do Estado.

\section{A RACIONALIDADE BECCARIANA PARA GOVERNANÇA}

Johnston e Shearing consideram o pensamento de Cesare Beccaria um exemplo da mentalidade punitiva aquém da resolução atual das questões sobre justiça e segurança, haja vista que a punição estatal é a principal ferramenta para manter a segurança numa sociedade ${ }^{25}$.

Destaca-se que Beccaria era um teórico do absolutismo esclarecido. Não estava tanto preocupado em denunciar os abusos de governantes, mas em defender o poder absoluto do rei e, complementarmente, o uso desse poder absoluto de acordo com a razão. Nesse sentido, se opôs à prática cruel da tortura e da pena de morte dos prisioneiros; apelou por leis transparentes que afirmassem o que é punível; argumentou uma aplicação limitada do uso da prisão preventiva; defendeu sanções razoáveis a gravidade do dano, que as sentenças penais devam ser proferidas o mais rapidamente possível e que os cidadãos devem se privar de parte de sua liberdade em prol do Estado ${ }^{26}$. Assim, Beccaria foi um

24 GARLAND, David. Ad contradições da "sociedade punitiva": o caso britânico. Discursos sediciosos: crime, direito e sociedade. a. 7, n. 11. Rio de Janeiro: Editora Revan, 2002, p. 81.

${ }^{25}$ QUADERNI FIORENTINI PER LA STORIA DEL PENSIERO GIURIDICO MODERNO, Milano: Giuffrè, vol. 36 [due tomi]: Principio di legalità e diritto penale (per Mario Sbriccoli). In: FRANCESCO, Giovannangelo de. Funzioni dela pena e limiti dela coercizione: caratteri ed eredità del

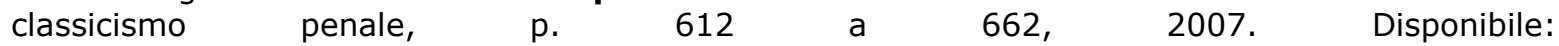
<http://www.centropgm.unifi.it/quaderni/36/volume.pdf\#page=612>. Accesso: 13 nov. 2015. p. $90-91$.

26 Beccaria foi um pensador que tentou encontrar um equilíbrio entre instrumentalidade (utilitarismo) e legal (contrato social). 
DELGADO, Joedson de Souza. A governança da justiça e da segurança na sociedade de risco contemporânea. Revista Eletrônica Direito e Política, Programa de Pós-Graduação Stricto Sensu em Ciência Jurídica da UNIVALI, Itajaí, v.11, n.1, 10 quadrimestre de 2016. Disponível em: www.univali.br/direitoepolitica - ISSN 1980-7791.

grande promotor da modernização da pena de acordo os valores e ideias do Iluminismo.

De outra banda, Beccaria é um inovador teórico da conexão entre racionalidade e normatividade ${ }^{27}$. Queria mostrar a teoria do contrato social na qual as pessoas racionalmente podem transferir uma parte da sua liberdade para o Estado em favor da própria segurança. A racionalidade desta transferência exige que as pessoas não deem mais liberdade do que é necessário para sua segurança. Os pontos de vista de Beccaria sobre o direito penal e o contrato social se relacionam com diferentes níveis de raciocínio humano.

Em função disso, Beccaria acreditava que as pessoas são guiadas pela busca do prazer e evitam a dor ${ }^{28}$. Alguns crimes podem proporcionar prazer e, portanto, a punição deve produzir mais desvantagem do que a vantagem do crime. Os homens são controlados por estímulo direto de seus sentidos e, portanto, punição imediata seria mais eficaz contra o crime. Portanto, o primeiro nível refere-se a capacidade de algumas pessoas em examinar os benefícios imediatos do crime contra as desvantagens de punição, portanto, o tempo entre o crime e a punição não deve demorar. $O$ segundo nível de questionamento da racionalidade refere-se a capacidade das pessoas de sopesar as vantagens e desvantagens, a curto e longo prazo através de uma punição rápida. O terceiro nível é quando as pessoas são capazes de internalizar em um patamar mais elevado de abstração e, para tanto, requer a descrição destes comportamentos acessíveis ao público e consagrados na lei.

Outrossim, a reconciliação entre o comportamento após o cumprimento da pena e a lei presume o funcionamento de um sistema cuja tônica pressupõe um raciocínio abstrato entre homens capazes de ler e entender a conjuntura política. Raciocínio abstrato, portanto, não apenas para a literalidade normativa, mas também sobre o sistema jurídico e político em que esses textos têm sua tessitura. Isso fornece um quarto nível de abstração de que as pessoas são

27 RI JÚNIOR, Arno Dal et al. Iluminismo e direito penal. Florianópolis: Editora Fundação Boiteux, 2009, p. 167.

${ }^{28}$ RI JÚNIOR, Arno Dal et al. Iluminismo e direito penal. p. 57. 
DELGADO, Joedson de Souza. A governança da justiça e da segurança na sociedade de risco contemporânea. Revista Eletrônica Direito e Política, Programa de Pós-Graduação Stricto Sensu em Ciência Jurídica da UNIVALI, Itajaí, v.11, n.1, $1^{0}$ quadrimestre de 2016. Disponível em: www.univali.br/direitoepolitica - ISSN 1980-7791.

capazes de compreender o funcionamento do sistema pelas leis. Por exemplo, o fato de que um sistema legal é parte de uma democracia, com benefícios para todos, pode desempenhar um papel no impedimento de a prática delitiva. Beccaria, então, presume sobre a eficácia das leis penais outrora promulgadas.

No que concerne à teoria do contrato social, Beccaria adiciona ao nível jurídico e político de abstração, um quinto nível da racionalidade ${ }^{29}$ em que as pessoas são capazes de compreender as sanções legais como, também, de avaliar a transferência da liberdade pelo cálculo das vantagens e desvantagens do estado natural em relação ao sistema político vigente, isto é, avaliam quanta liberdade deve ser abandonada em favor da proteção e segurança. Portanto, o quinto nível de abstração reconhece que as pessoas raciocinam a partir de seus próprios interesses como motivo racional para suas ações. Neste aspecto, descobriu que pode ser mais benéfico para um indivíduo desrespeitar as normas do que cumprir como os demais cidadãos.

Ao debruçar-se sobre a natureza do problema, Beccaria observou que as pessoas aderem às leis quando as sanções ocorrem por motivos concretos. Tal questionamento aponta as razões pelas quais as pessoas se juntam ao contrato social sem a implementação dessas sanções. Beccaria argumentou a vontade racional como base, mas ao mesmo tempo indicou que muitas pessoas aderem apenas a uma legislação sob ameaça de punição ${ }^{30}$. Um deslinde para este impasse está no contrato social, visto como uma permissão para as autoridades estatais punirem os transgressores da lei. Aqui, um sexto nível permitiu que as pessoas trouxessem uma solução para o conflito entre $o$ autointeresse $\mathrm{e}$ utilidade social.

Nestes termos, a reconstrução do pensamento de Beccaria pode explicar a eficácia de uma lei aprovada no combate ao crime. Quando todos os cidadãos são capazes de pensar os seis níveis de racionalidade diante de leis cognoscíveis

\footnotetext{
${ }^{29}$ RI JÚNIOR, Arno Dal et al. Iluminismo e direito penal. p. 102-112.

${ }^{30}$ RI JÚNIOR, Arno Dal et al. Iluminismo e direito penal. p. 88-98.
} 
DELGADO, Joedson de Souza. A governança da justiça e da segurança na sociedade de risco contemporânea. Revista Eletrônica Direito e Política, Programa de Pós-Graduação Stricto Sensu em Ciência Jurídica da UNIVALI, Itajaí, v.11, n.1, $1^{0}$ quadrimestre de 2016. Disponível em: www.univali.br/direitoepolitica - ISSN 1980-7791.

e de uma justiça criminal capaz de impor sanções ágeis e proporcionais, o direito penal irá cumprir os ideais beccariano de eficácia e normatividade.

Contudo, o que se vê, na atualidade, é o fracasso da engenharia social que tem se mostrado incapaz de responder prontamente as transgressões. Isso elimina um elemento-chave do pensamento de Beccaria referente ao cumprimento da lei desde que os cidadãos forem efetivamente punidos ${ }^{31}$. A explicação para a ineficácia da lei penal pode ser buscada em uma falta de racionalidade dos cidadãos que não são capazes de responder adequadamente as ameaças e sanções do tipo penal, por exemplo, o furto famélico incapacita os cidadãos de entender o sistema político ou de aceitar o contrato social como legítimo.

É possível que a teoria de Beccaria esteja incorreta ou incompleta e que outras explicações são ou seriam mais indicadas para o aumento da criminalidade e para o fracasso da lei criminal, visto que elucidações políticas, econômicas e culturais estão ausentes de sua retórica que concentra-se no discurso sobre liberdade e segurança. Neste aspecto, Arruda pondera de que forma a sociedade responde ao crime, pois é parcialmente determinada pelas estruturas políticas e econômicas da sociedade ${ }^{32}$. O fato é que as sociedades igualitárias reagem menos duramente com a criminalidade do que sociedades com enormes diferenças econômicas. Neste sentido, aparentemente há um nexo entre a gravidade do crime e a distribuição igual ou desigual da riqueza.

Young aponta que o crime poderia, então, ser explicado pela privação daqueles que estão na parte inferior da sociedade ${ }^{33}$. Nesse caso, a resposta penal ao crime poderia reforçar o sentimento de injustiça que perpassa a riqueza em uma sociedade desigual. Esse fato permite que um sétimo nível seja acrescentado ao pensamento racional beccariano: pessoas que coerentemente avaliam o papel da

\footnotetext{
${ }^{31}$ RI JÚNIOR, Arno Dal et al. Iluminismo e direito penal. p. 12-21.

32 ARRUDA, José Maria. O Dilema do Prisioneiro e suas implicações éticas. In: Revista Humanidades. Fortaleza, v. 19, n. 2, p. 67-73, jul./dez. 2004. Disponível em: <http://hp.unifor.br/pdfs_notitia/1557.pdf>. Acesso em: 8 set. 2015.

33 YOUNG, Jock. A Sociedade Excludente - Exclusão social, criminologia e diferença na modernidade recente. Rio de Janeiro: Revan, 2002, 314p.
} 
DELGADO, Joedson de Souza. A governança da justiça e da segurança na sociedade de risco contemporânea. Revista Eletrônica Direito e Política, Programa de Pós-Graduação Stricto Sensu em Ciência Jurídica da UNIVALI, Itajaí, v.11, n.1, 10 quadrimestre de 2016. Disponível em: www.univali.br/direitoepolitica - ISSN 1980-7791.

justiça da sociedade têm uma razão para aderir às leis penais, assumindo que são capazes de vivenciar sobre os seis primeiros níveis de racionalidade.

É possível que esta explicação de pensamento mais abstrato seja incorreta e que uma análise beccariana da racionalidade e de sanções penais sejam incompatíveis com a natureza humana e com a realidade social. As pessoas não decidem sobre um ou mais níveis de racionalidade, portanto, a teoria e os sistemas sociais não são voltados para decisões racionais das pessoas, de certo modo, os fatores precisam ser mais bem explicados.

É sob essa perspectiva examino as declarações que indicam por que o Estado não consegue manter a segurança usando apenas a lei penal e o porquê das ferramentas de segurança alternativas são necessárias.

\section{EXPLICAÇÕES ATUAIS PARA A GOVERNANÇA}

De acordo com a teoria beccariana, se o governo não fornece segurança plena às pessoas em certa medida acabam no "estado de natureza" descrito por Hobbes e, portanto, procuram alternativas para o seu resguardo pessoal, familiar e/ou comercial $^{34}$. A governança da justiça e da segurança pública poderia, portanto, ser expressa pela teoria do contrato social na busca de alternativa ou de complementar a segurança em relação ao "estado de natureza", a exemplo, da contratação de serviços privados de segurança.

No campo conceitual, Kaufmann, Kraay e Mastruzzi entendem que a governança ocorre por "costume e instituições pelas quais a soberania é exercida" que incluem

o processo pelo qual os governos são selecionados, monitorizados e substituídos; a capacidade do governo para formular e eficazmente implementar políticas sólidas; o

34 O "estado de natureza" é sempre um estado de guerra: mesmo que não haja batalha, ela está latente, podendo ocorrer a qualquer momento e sem causa aparente. Preocupados em se defender ou atacar, todos seres humanos se tornam incapazes de gerar riquezas. (HOBBES, Thomas. Leviatã ou a matéria, forma e poder de um estado eclesiástico civil. 2a. ed. São Paulo: Martin Claret, 2008.) 
DELGADO, Joedson de Souza. A governança da justiça e da segurança na sociedade de risco contemporânea. Revista Eletrônica Direito e Política, Programa de Pós-Graduação Stricto Sensu em Ciência Jurídica da UNIVALI, Itajaí, v.11, n.1, $1^{0}$ quadrimestre de 2016. Disponível em: www.univali.br/direitoepolitica - ISSN 1980-7791.

respeito dos cidadãos e do Estado para as instituições que governam as interações econômicas e sociais entre eles ${ }^{35}$.

De acordo com o pensamento de Beccaria, a maioria das pessoas, no que respeita à governança da segurança pública, utiliza o raciocínio em um ou mais níveis. Quando capazes de raciocinar no sexto ou sétimo nível podem concluir que sua segurança não deve se concentrar exclusivamente no Estado, mas que devem adotar medidas pessoais que garantam sua proteção. Neste sentido, Sutil assevera que

hoje, os governos estão diminuindo seus papeis. Estão também se tornando menos importantes como fóruns de participação e como veículos de mobilização social. [...] A maioria dos processos de decisão e muito do poder que o governo está perdendo estão sendo transferidos para o mercado ${ }^{36}$.

Em todo o caso, a transferência de liberdade para o cidadão não tem o efeito desejado, isto é, de que esteja melhor protegido. Portanto, a governança da justiça e da segurança pública aparece como um estado intermediário situado entre o monopólio estatal da função punitiva dos indivíduos e da luta de todos contra todos no "estado de natureza".

É inegável uma ambivalência de enfrentar a adversidade e de elaborar novas estratégias de governança da justiça e da segurança, mas do outro lado são adaptações de validar a narrativa da autoridade estatal. Nas palavras de Garland:

A difícil situação que os governos devem enfrentar reside no fato de que eles não podem mais ser o principal provedor da segurança e da repressão criminal, sabendo que, a curto prazo, professar essa função pública tem tudo para ser um desastre político.

\footnotetext{
35 KAUFMANN, Daniel; KRAAY, Aart; MASTRUZZI, Massimo. Governance matters VIII: aggregate and individual governance indicators, 1996-2008. World bank policy research working paper, $\mathrm{n}$. 4978, 2009.

36 SUTIL, Jorge Correa. Reformas Judiciárias na América Latina: Boas Notícias para os nãoprivilegiados. In: Democracia, violência e injustiça: o Não-Estado de direito na América Latina. MENDÉZ, Juan E.; O’DONELL, Guillermo; PINHEIRO, Paulo Sérgio. (Org.) São Paulo: Editora Paz e Terra, 2000, p. 295.
} 
DELGADO, Joedson de Souza. A governança da justiça e da segurança na sociedade de risco contemporânea. Revista Eletrônica Direito e Política, Programa de Pós-Graduação Stricto Sensu em Ciência Jurídica da UNIVALI, Itajaí, v.11, n.1, $1^{0}$ quadrimestre de 2016. Disponível em: www.univali.br/direitoepolitica - ISSN 1980-7791.

Por esta perspectiva, as pessoas transferem contratualmente sua liberdade para o Estado, no entanto, existem transições graduais entre o "estado da natureza" e o monopólio estatal referente à preocupação de segurança. À medida que as pessoas desistem de sua liberdade para o Estado, de acordo com a teoria beccariana, ocorre uma avaliação racional das vantagens e desvantagens desta transferência em favor de sua proteção.

Nozick argumenta que as pessoas não têm um contrato social para excluir do "estado de natureza" ao fazer sua própria segurança. As pessoas podem transferir sua liberdade às associações em favorecimento à execução de fins públicos. Defende, também, que é possível materializar a proteção individual e coletiva de forma otimizada através de um contrato social pelo mercado de vigilância privada ${ }^{37}$.

Nesse cenário de liberdade individual, as pessoas podem ser protegerem no contexto do Estado de Direito. Para Johnston e Shearing, a sociedade de rede não deve ser regulada pelo direito penal ${ }^{38}$, mas por outras formas que Reiner denomina de regulação da pluralidade por arranjos de segurança estatal ${ }^{39}$.

Com efeito, Johnston e Shearing asseveram que os cidadãos devem se resguardar usando diferentes direitos e liberdades por meio da contratação de segurança privada em áreas privadas ${ }^{40}$. Vislumbra-se, então, que o modelo de Beccaria é incompleto por não apresentar alternativa à governança da justiça e da segurança estando, portanto, ausente às garantias de segurança pessoal por instrumentos adicionais.

Como afirma Marins

A atual governança - utilizando terminologia em voga baseia-se num modelo mixed administration, propondo uma nova ordenação das funções governamentais. Reformula-se,

\footnotetext{
37 NOZICK, Robert. Anarquia, Estado e Utopia. Rio de Janeiro: Jorge Zahar, 1991, p. 245-256.

38 NOZICK, Robert. Anarquia, Estado e Utopia. p. 80-98.

39 REINER, Robert. A Política da Polícia. Tradução: Jacy Cardia Ghirotti e Maria Cristina Pereira da Cunha Marques. São Paulo; Editora da Universidade de São Paulo, 2004.

40 REINER, Robert. A Política da Polícia. p. 44-61.
} 
DELGADO, Joedson de Souza. A governança da justiça e da segurança na sociedade de risco contemporânea. Revista Eletrônica Direito e Política, Programa de Pós-Graduação Stricto Sensu em Ciência Jurídica da UNIVALI, Itajaí, v.11, n.1, $1^{0}$ quadrimestre de 2016. Disponível em: www.univali.br/direitoepolitica - ISSN 1980-7791.

por sua vez, o desempenho da iniciativa privada: o particular, nesse novo cenário, não é mais súdito ou sujeito descompromissado, nem tampouco mero utente de serviços; pelo contrário, assume o papel de ator, partilhando com o Poder Público responsabilidades na realização do interesse público ${ }^{41}$.

Portanto qual é a melhor opção para a governança da justiça e da segurança resguardando a liberdade de escolha das pessoas? O mercado de segurança privada tem uma grande limitação em relação à segurança proporcionada pelo Estado. No geral, os particulares não podem fazer uso da força para autodefender, a exemplo, das restrições à posse de arma de fogo. Trata-se de uma diferença limitadora do "estado de natureza", logo, o contrato social, de acordo com o modelo de Beccaria, tem como principal objetivo a monopolização estatal do instrumento da coerção entre os particulares perpetrados pela vingança.

Sob esta perspectiva, o governo e a sociedade civil organizada perceberam um novo fato social em transformação "na percepção oficial do crime, no discurso da criminologia, nas modalidades de ação do governo, e finalmente, na estrutura das organizações da justiça criminal ${ }^{42 " . ~ C o m ~ i s s o, ~ q u e s t i o n a ~ s e ~ o s ~ a r r a n j o s ~}$ baseados nos direitos privados são eficazes à proteção pessoal e a segurança patrimonial, já que "a segurança privada é um componente indispensável ao sistema de segurança interna, revelando-se como um dos elementos da intricada teia de controle social ${ }^{43} . "$.

Com base no modelo beccariano questiona-se o manejo de funções públicas por particulares e em que medida sua utilização é proporcional à liberdade. Indagase também se a governança da justiça e da segurança leva a igual proteção ou apenas a sua desigualdade, em razão de que algumas pessoas têm maiores recursos financeiras do que outros para fazer.

\footnotetext{
${ }^{41}$ ReINER, Robert. A Política da Polícia. p. 83.

42 GARLAND, David. Ad contradições da "sociedade punitiva": o caso britânico. Discursos sediciosos: crime, direito e sociedade. a. 7, n. 11. Rio de Janeiro: Editora Revan, 2002, p. 72.

43 GARLAND, David. Ad contradições da "sociedade punitiva": o caso britânico. Discursos sediciosos: crime, direito e sociedade. p. 93.
} 
DELGADO, Joedson de Souza. A governança da justiça e da segurança na sociedade de risco contemporânea. Revista Eletrônica Direito e Política, Programa de Pós-Graduação Stricto Sensu em Ciência Jurídica da UNIVALI, Itajaí, v.11, n.1, 10 quadrimestre de 2016. Disponível em: www.univali.br/direitoepolitica - ISSN 1980-7791.

Neste particular, subentende-se pelo pensamento beccariano que todos têm interesse pela proteção estatal, mas a segurança pode assumir interesses diversos que levem a escolhas de proteção, a exemplo dos condomínios residências ou comerciais tidos como refúgios seguros ao garantir acessibilidade às áreas comuns e proteção contra a criminalidade nas áreas inseguras localizadas fora do perímetro condominial.

As soluções para a segurança dos cidadãos dependem de uma análise das várias opções de racionalidade e de oportunidades oferecidas pelos atores sociais. Eventualmente repousa em uma avaliação racional que pode levar à conclusão de que as pessoas têm a sua liberdade em alguns casos, limitada a segurança que o Estado proporciona, mas aquém da satisfação coletiva.

\section{CONSIDERAÇÕES FINAIS}

Importante expoente das ideias iluministas no campo jurídico-penal, à época, Beccaria trabalhou para o processo de diferenciação entre sociedade civil e o Estado, pois inexistia uma distinção clara perante as duas esferas. O pensamento de Beccaria era voltado a superar uma situação em que a repressão aos comportamentos antissociais era levada a cabo fundamentalmente por corpos sociais periféricos da sociedade corporativa da transição da idade média para a modernidade, levando a um reforço do absolutismo monárquico na esfera penal.

$\mathrm{Na}$ atualidade, Johnston e Shearing vão além e discorrem que o Estado é uma condição necessária para novos acordos privados de proteção da segurança no sentido de definir os direitos de propriedade e liberdade contratual. Nesse sentido, a segurança pode ser refletida e promovida por uma série de atores das esferas públicas, empresariais e comunitárias que se influenciam mutuamente.

Os pressupostos deste pensamento é compreender os motivos da inovação e as condições que tornam possível a governança da segurança ao mapear as mentalidades e as práticas encontradas em uma variedade de setores, bem 
DELGADO, Joedson de Souza. A governança da justiça e da segurança na sociedade de risco contemporânea. Revista Eletrônica Direito e Política, Programa de Pós-Graduação Stricto Sensu em Ciência Jurídica da UNIVALI, Itajaí, v.11, n.1, $1^{0}$ quadrimestre de 2016. Disponível em: www.univali.br/direitoepolitica - ISSN 1980-7791.

como compreender os modos pelos quais o pensamento destes setores influência o outro.

A partir da teoria beccariana, questiona-se quais os instrumentos mais eficazes para proteger a segurança das pessoas já que tem implicações futuras para os valores democráticos sobre o papel tradicional dos governos que estão cada vez mais contestados.

Certo, porém, que a segurança se tornou uma característica definidora do discurso público contemporâneo, permeando por problemas de crimes diários, perturbação da ordem pública/privada e, atualmente, pela "guerra ao terror" sendo, com isso, fundamental para explicar e justificar a estruturação das redes sociais.

O pensamento de Beccaria encontra-se desatualizado, visto que o manuscrito Dei Delitti e delle Pene foi escrito há mais de 250 anos ${ }^{44}$, no entanto, algumas questões de governança da justiça e da segurança ainda estão presentes nos dilemas jurídico-penais contemporâneos. Desta feita, Beccaria rompeu o paradigma que visava adaptar o direito penal à fase absolutista do Estado moderno, em especial, ao absolutismo setecentista dos países periféricos da Europa.

Ressalta-se que as pessoas não são racionais de acordo com os ideais iluministas, e por este motivo, o Estado se respalda em não atender as concepções da eficácia e de normatividade encampando em seu lugar um livre mercado de segurança. Tal situação pode ser considerada uma erosão do monopólio estatal? Quem de fato considera que fracassou e pode pagar se reclusam em condomínios, enquanto aqueles que não podem ficam à mercê das áreas assemelhadas ao "estado natural" de Hobbes.

\section{REFERÊNCIAS DAS FONTES CITADAS}

${ }^{44}$ Cesare Beccaria escreveu Dei Delitti e delle Pene no século XVIII (entre o final de 1763 e início de1764) com publicação da obra nos primeiros meses. 
DELGADO, Joedson de Souza. A governança da justiça e da segurança na sociedade de risco contemporânea. Revista Eletrônica Direito e Política, Programa de Pós-Graduação Stricto Sensu em Ciência Jurídica da UNIVALI, Itajaí, v.11, n.1, $1^{\circ}$ quadrimestre de 2016. Disponível em: www.univali.br/direitoepolitica - ISSN 1980-7791.

ALVES, Luís Cláudio. Audiência discute destinação de postos comunitários de segurança. Disponível em: <http://www.cl.df.gov.br/ultimas-noticias//asset_publisher/ITOh/content/audiencia-discute-destinacao-de-postoscomunitarios-deseguranca; jsessionid=2B76A1A65DF2D8CCDF093DC36C9382DE. liferay2 ? redirect =http \%3A\%2F\%2Fwww.cl.df.gov.br\%2Fnoticias>. Acesso em: 11set. 2015.

ARRUDA, José Maria. O Dilema do Prisioneiro e suas implicações éticas. In: Revista Humanidades. Fortaleza, v. 19, n. 2, p. 67-73, jul./dez. 2004. Disponível em: <http://hp.unifor.br/pdfs_notitia/1557.pdf>. Acesso em: 8 set. 2015.

BECK, Ulrich. World risk society. Cambridge: Polity Press, 1999.

DUPONT, Benoît. As redes de segurança. In: SLAKMON, Catherine; MACHADO, Maíra Rocha; BOTTINI, Pierpaolo Cruz (Org.). Novas direções na governança da justiça e da segurança. Brasília-DF: Ministério da Justiça, 2006, p. 707718.

<http://www.esteio.rs.gov.br/documents/SMSMU/governanca\%20na\%20segura nca\%20-\%20material\%20do\%20MJ.pdf >. Acesso em: 08 set. 2015.

GARLAND, David. Ad contradições da "sociedade punitiva": o caso britânico. Discursos sediciosos: crime, direito e sociedade. a. 7, n. 11 . Rio de Janeiro: Editora Revan, 2002, p. 69 a 92.

HOBBES, Thomas. Leviatã ou a matéria, forma e poder de um estado eclesiástico civil. 2a. ed. São Paulo: Martin Claret, 2008.

JOHNSTON, Les; SHEARING, Clifford. A justiça em sociedades de risco. In: SLAKMON, Catherine; MACHADO, Maíra Rocha; BOTTINI, Pierpaolo Cruz (Org.). Novas direções na governança da justiça e da segurança. Brasília-DF: Ministério da Justiça, 2006, p. 131-146. Disponível em: <http://www.esteio.rs.gov.br/documents/SMSMU/governanca\%20na\%20segura nca\%20-\%20material\%20do\%20MJ.pdf>. Acesso em: 08 set. 2015.

KAUFMANN, Daniel; KRAAY, Aart; MASTRUZZI, Massimo. Governance matters VIII: aggregate and individual governance indicators, 1996-2008. World bank policy research working paper, n. 4978, 2009.

LIMA, Lincoln de Oliveira. Estratégias de policiamento preventivo: "indiferença zero", uma boa experiência de polícia. Assis: Triunfal Gráfica e Editora, 2011.

MARINS, Vinicius. Contratação de serviços de segurança privada pela administração pública: uma análise à luz da moderna privatização de poderes administrativos. In: Revista do Tribunal de Contas do Estado de Minas Gerais. V. 74, n. 1, ano XXVIII, 2010. Disponível em: <http://revista.tce.mg.gov.br/Content/Upload/Materia/854.pdf>. Acesso em: 08 set. 2015. 
DELGADO, Joedson de Souza. A governança da justiça e da segurança na sociedade de risco contemporânea. Revista Eletrônica Direito e Política, Programa de Pós-Graduação Stricto Sensu em Ciência Jurídica da UNIVALI, Itajaí, v.11, n.1, $1^{\circ}$ quadrimestre de 2016. Disponível em: www.univali.br/direitoepolitica - ISSN 1980-7791.

NOZICK, Robert. Anarquia, Estado e Utopia. Rio de Janeiro: Jorge Zahar, 1991.

QUADERNI FIORENTINI PER LA STORIA DEL PENSIERO GIURIDICO MODERNO, Milano: Giuffrè, vol. 36 [due tomi]: Principio di legalità e diritto penale (per Mario Sbriccoli). In: FRANCESCO, Giovannangelo de. Funzioni dela pena e limiti dela coercizione: caratteri ed eredità del classicismo penale, 2007. Disponibile:

<http://www.centropgm.unifi.it/quaderni/36/volume.pdf\#page=612>. Accesso: 13 nov. 2015.

REINER, Robert. A Política da Polícia. Tradução: Jacy Cardia Ghirotti e Maria Cristina Pereira da Cunha Marques. São Paulo; Editora da Universidade de São Paulo, 2004.

RI JÚNIOR, Arno Dal et al. Iluminismo e direito penal. Florianópolis: Editora Fundação Boiteux, 2009.

RI JÚNIOR, Arno Dal; CASTRO, Alexander de. Iluminismo e absolutismo no modelo jurídico-penal de Cesare Beccaria. In: Revista Seqüência, n. 57, p. 261-284, dez. 2008. Disponível em: <http://dx.doi.org/10.5007/21777055.2008v29n57p261>. Acesso em: 13 nov. 2015.

SUTIL, Jorge Correa. Reformas Judiciárias na América Latina: Boas Notícias para os não-privilegiados. In: Democracia, violência e injustiça: o Não-Estado de direito na América Latina. MENDÉZ, Juan E.; O'DONELL, Guillermo; PINHEIRO, Paulo Sérgio. (Org.) São Paulo: Editora Paz e Terra, 2000.

WOOD, Jennifer; MARKS, Monique. Governança conexa: desenvolvendo novas ideias para a segurança e a justiça. In: SLAKMON, Catherine; MACHADO, Maíra Rocha; BOTTINI, Pierpaolo Cruz (Org.). Novas direções na governança da justiça e da segurança. Brasília-DF: Ministério da Justiça, 2006, p. 719-737. Disponível em: <http://www.esteio.rs.gov.br/documents/SMSMU/governanca\%20na\%20segura nca\%20-\%20material\%20do\%20MJ.pdf >. Acesso em: 08 set. 2015.

YOUNG, Jock. A Sociedade Excludente - Exclusão social, criminologia e diferença na modernidade recente. Rio de Janeiro: Revan, 2002.

ZANETIC, André. Segurança privada: características do setor e impacto sobre o policiamento. In: Revista Brasileira de Segurança Pública. Ano 3, ed. 4, mar/abr 2009. Disponível em: <http://revista.forumseguranca.org.br/index.php/rbsp/article/view/44/42>.

Acesso em: 08 set. 2015.

Submetido em: Novembro/2015

Aprovado em: Abril/2016 